Pak. j. sci. ind. res. Ser. A: phys. sci. 2020 63A(3) 220-230

\title{
Review
}

\section{Molybdenum Disulfide for Different Applications -A Review}

\author{
Tahir Iqbal $^{a *}$, Memoona Kousar $^{\mathrm{b}}$, Aqsa Tehseen $^{\mathrm{c}}$ and Almas Bashir ${ }^{\mathrm{d}}$ \\ Department of Physics, University of Gujrat, Hafiz Hayat Campus, Gujrat, 50700, Pakistan
}

(received October 30, 2018; revised August 15, 2019; accepted August 19, 2019)

\begin{abstract}
MoS}_{2}$ is a layered evolution metal having similar structure to graphene. It has got universal consideration due to its different applications as sensors, energy storage devices, energy adaptation and environmental remediation. The properties of $\mathrm{MoS}_{2}$ and graphene are almost comparable but $\mathrm{MoS}_{2}$ has higher tendency than graphene because it has a low cost, tunable band gap and good visibility for light absorption properties. So, our main focus is to elaborate the up-to-date advances of $\mathrm{MoS}_{2}$ with respect to applications of energy and environment at broad area, for example, applications in HER, Li-ion battery, dye sensitized soar cells and super capacitors. At last the submission of energy and environmental for challenges to design $\mathrm{MoS}_{2}$ are painted. But $\mathrm{MoS}_{2}$ also has some limitations as a good photo catalyst which are discussed in this review article. In this study, we systematically explore the recent researches on transition metal doped $\mathrm{MoS}_{2}$ as photo catalyst for hydrogen evolution by splitting the water.
\end{abstract}

Keywords: hydrogen evolution reaction, super capacitor, photo catalysis, graphene, Li-ion battery, sensors, molybdenum disulfide, fossil fuels, dye-sensitized solar cells

\section{Introduction}

In universal economy, the quick progress of industrialization and human civilization has created severe problems (Ge et al., 2016; Xiong, 2016; Zhang et al., 2016; Wang et al., 2015; Zhu et al., 2012). Now a days, the most serious challenges of space are the safety of utilization of energy and environment. Many other materials like $\mathrm{TiO}_{2}$ and $\mathrm{Cd} \mathrm{S}$ are also used for these procedures but there is a need of other material for their replacement because these materials are costly and not earth abundant. The best option to replace these materials is $\mathrm{MoS}_{2}$. The physical properties of $\mathrm{MoS}_{2}$ are like graphene but $\mathrm{MoS}_{2}$ it is superior to graphene due to low cost, tunable bandgap and its more abundance. $\mathrm{MoS}_{2}$ is a unique combination of properties as structural, optical, chemical, thermal and mechanical properties that make it attractive for specific applications (Chhowalla et al., 2013; Zeng et al., 2011). Bulk $\mathrm{MoS}_{2}$ with unintended band gap of $1.2 \mathrm{eV}$ is semiconducting. $\mathrm{MoS}_{2}$ belongs to the class of transition metal dichalcogenide (TMDs) (Butler et al., 2013; Novoselov et al., 2004).

It appears in the Earth's crust naturally as mineral. It is not different from other elements such as graphite or leads. By the ancient Greek, it was called molybdos

*Author for correspondence;

E-mail: almasbashir001@gmail.com means beadlike. Molaybdenum is snack between two sulfur layers. The representative of $2 \mathrm{D}$ materials is graphene that has zero energy gap which results in stimulating applications and stimulating properties. Usually, major energy sources such as oil, coal and usual gas are non renewable. Our $80 \%$ current sources of energy production are fossil fuels. But this source of energy is main cause of global warming and climate change (Kim et al., 2014; Snyder et al., 2013). Because of fossil fuel, the amount of $\mathrm{CO}_{2}$ increased in environment. To solve the significant problems of atmosphere and energy, we must develop highly active catalytic materials. Four polytypic of $\mathrm{MoS}_{2}$ are discovered after many year's research, viz $1 \mathrm{~T} \mathrm{MoS}_{2}, 1 \mathrm{H}$ $\mathrm{MoS}_{2}, 2 \mathrm{H} \mathrm{MoS}$ and 3R MoS 2 (Imanishi and Takehara, 1992). After the successful research in graphene, other single layer 2D materials such as Boron nitride (BN) and TMDs are also established great potential due to their unique electronic and structural properties. $\mathrm{MoS}_{2}$ is also one of the most studied 2D materials which attracted much attention. $\mathrm{MoS}_{2}$ is a closest competitor of graphene and used as its substitute, because of its reasonable energy gap, mechanical flexibility, absence of dangling bonds, chemical and thermal stability. We shall focus on $\mathrm{MoS}_{2}$ advances nan ostructured materials in the field of environment and energy in this review. There are most useful technologies to overcome the 
energy and environment related problems; such as Solar cell, Super capacitor, Li-ion-battery and hydrogen evolution reaction (Zhang et al., 2016).

Structure and preparation of $\mathbf{M o S}_{2}$. In 1923, Pauling and Dickson introduced the positions of Mo and $\mathrm{S}$ in hexagonal structure of $\mathrm{MoS}_{2}$ by using theory of space groups and photographs. They also investigated that Mo and S were stacked along c-axis in S-MO-S layered structure. In 1966, Frindt et al. determined that thin sheets of $\mathrm{MoS}_{2}$ with thickness 1.2-1.5 nm will be obtained by micromechanical peeling technique. In 1986 , by using lithium intercalation followed by exfoliation in water to obtain the $\mathrm{MoS}_{2}$. In 1986, Yoshimura et al. using the Vander Waals epitaxial to obtained single layer $\mathrm{MoS}_{2}$ (Koma and Yoshimura, 1986). In 1991, Frindt et al. investigated the structure of $\mathrm{MoS}_{2}$ by using exfoliation of lithium intercalated $\mathrm{MoS}_{2}$ powder. The $\mathrm{MoS}_{2}$ belonged to class transition metal dichalcogenide (TMDs). The TMD was generally characterized by the formula: $\mathrm{MX}_{2}$, where $\mathrm{M}$ was transition metal element from groups IV, V and VI of periodic table and $\mathrm{X}$ was chalcogen species $\mathrm{S}$, Se and Te. The electronic characteristics could be metallic, semiconducting or superconducting TMDs of family material. $\mathrm{MoS}_{2}$ had hexagonal layered crystal structure. Mo layer is sandwiched between two sulfur layers. The unique structure of $\mathrm{MoS}_{2}$ has many promising properties, such as anisotropy antiproton corrosion and chemical stability.

Crystalline phases. After many years research, the researchers determined that there were four polytypes of $\mathrm{MoS}_{2}$ which were $1 \mathrm{H}, 1 \mathrm{~T}, 2 \mathrm{H}$ and $3 \mathrm{R}$ where $\mathrm{T}, \mathrm{H}$, $\mathrm{R}$ stands for tetragonal, hexagonal and rhombohedra respectively. Here numbers determined the S-Mo-S layers per unit cell as shown in Fig. 1. Among them $1 \mathrm{H}$ and $2 \mathrm{H}$ were most stable and $1 \mathrm{~T}$ and $3 \mathrm{R}$ were metastable polytypes. The cohesive energy of $15.55 \mathrm{eV}$ per cell was found to optimize the $1 \mathrm{H} \mathrm{MoS}_{2}$. $1 \mathrm{H} \mathrm{MoS}$ had low confrontation to bending and strain is exposed $\sim 10 \%$ without failure. $2 \mathrm{H} \mathrm{MoS}$ had trigonal prismatic coordination around the Mo atom with two layers per unit cell with lattice constants of $\mathrm{a}=3.16 \mathrm{~A}^{\circ}$ and $\mathrm{c}=12.29 \mathrm{~A}^{\circ}$ that belonged to the space group of $\mathrm{P} 63 / \mathrm{mmc}$. $2 \mathrm{H} \mathrm{MoS}$ had non-bonding d orbitals that were fully occupied and this led to semiconducting behaviour. The $2 \mathrm{H}-\mathrm{MoS}_{2}$ was most common polymorph phase which could be transformed from semiconductor into the metallic $1 \mathrm{~T}$ phase by using phase engineering. $3 \mathrm{R} \mathrm{MoS}_{2}$ was similar to $2 \mathrm{H} \mathrm{MoS}_{2}$ but it had three layers per unit

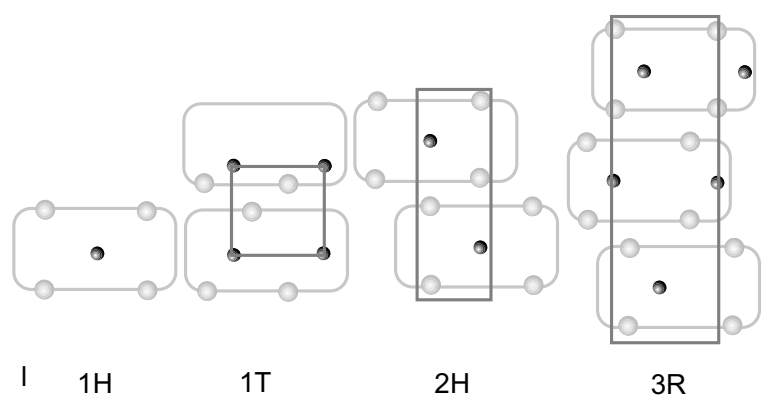

Fig. 1. Systematic diagram of common polytypes of $\mathrm{MoS}_{2}$ (Benavente et al., 2002).

cell with lattice constants of $\mathrm{a}=3.17 \mathrm{~A}^{\circ}$ and $\mathrm{c}=18.38 \mathrm{~A}^{\circ}$ that belong to the space group R3m (Goloveshkin et al., 2013). To form a unit cell, molybdenum atoms octahedrally coordinated by the sulfur and molybdenum atoms in $1 \mathrm{~T} \mathrm{MoS}_{2}$. In $1 \mathrm{~T} \mathrm{MoS}$ the non-bonding $\mathrm{d}$ orbitals were partially occupied and this contribute to metallic conductivity.

Applications of $\mathbf{M o S}_{2}$. For the financial improvement of state and ecological dominance, energy is significant input. Fossil fuel provides over $80 \%$ current energy tradition. However, amount of $\mathrm{CO}_{2}$ liberates from flaming of fossil fuels which is a main cause of climate change and global warming. Therefore, it is essential to introduce extremely active catalyst to resolve serious problems associated to energy and environment. By using these applications of $\mathrm{MoS}_{2}$ as renewable energy sources, energy can be produced and stored without effecting the environment as the other sources of energy, solar system is a best option to produce energy but it has also its side effects. (Santhosh and Madhavan, 2019) The two-dimensional graphene like $\mathrm{MoS}_{2}$ had almost same functional properties such as high transportation of charge carrier, good mechanical friction, excellent electronic and optical properties. All these extraordinary properties of $\mathrm{MoS}_{2}$ are valuable in different applications including energy conversion and storage, lubricants, catalysts, environment remediation, water degradation to remove heavy metal and purify drinking water under visible light. $\mathrm{MoS}_{2}$ had low cost, tunable bandgap and good visible light assimilation capacity and these properties are better than graphene. If energy is produced by using solar system, there will be rise in the amount of $\mathrm{CO}_{2}$ which cause environment pollution. So, it is an urgent necessity of materials or sources which can replace the previous sources. $\mathrm{MoS}_{2}$ provided that to be a adaptable material for an extensive variety of 


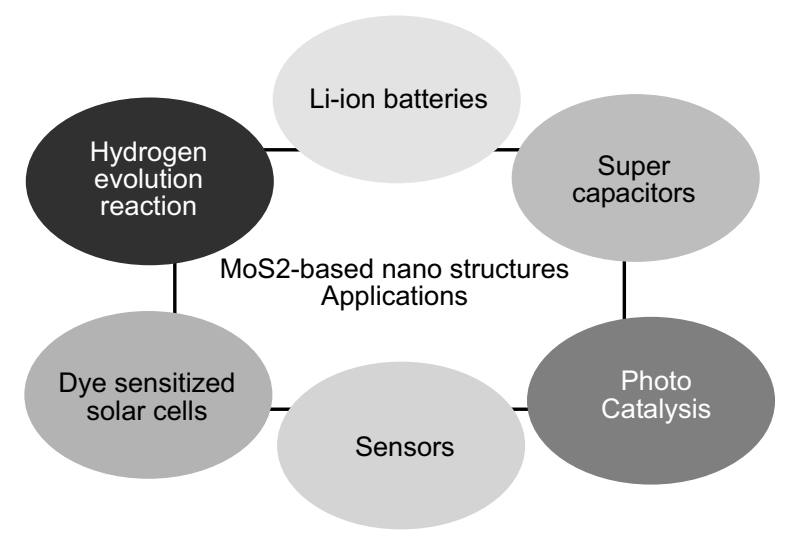

Fig. 2. Applications of $\mathrm{MoS}_{2}$-based nano structures.

applications such as lithium ion batteries, dye synthesized solar cell, super capacitor and hydrogen evolution reaction (Arshad et al., 2019; Lou et al., 2008) as shown in Fig. 2.

Lithium ion batteries (LIB's). One of the most important concern in our daily life is energy due to its increasing demand in $21^{\text {st }}$ century, since in 1990 by Sony corporation the first commercialization of LIBs (Long et al., 2016). Li-ion batteries (LIBs) have become the mostly effective energy storage devices, among all rechargeable batteries. From last two eras, there is sudden enlargement and immense potential in many applications, but the commercialization of LIB's is immobile slow for modern technologies due to their short life period and poor dependability. These things are associated to partiality of the materials (Long et al., 2016). LIB's will need appropriate material for commercialization. In this way, its protection and lifetime can be recovered. Many transition materials are accomplished for behaving as LIB anode materials, transition materials are following: $\mathrm{Co}_{3} \mathrm{O}_{4}$ (Lou et al., 2008) $\mathrm{TiO}_{2}, \mathrm{NiO}_{2}$ (Zhu et al., 2012) and $\mathrm{Mn}_{3} \mathrm{O}_{4}$. But $\mathrm{MoO}_{2}$ is special candidate with theoretical precise capability of $838 \mathrm{mAh} / \mathrm{g}$ as LIB anode material. Recently, many information is published on LIB anode materials that are $\mathrm{MoS}_{2}$ based. $\mathrm{MoS}_{2}$ based materials are as anode and cathode in LIB's because of their high capacitance (Qu et al., 2017; Yu et al., 2014; Zhang et al., 2014; Shi et al., 2013). CLET $\mathrm{MoS}_{2}$ showed very good result with much better cyclic solidity than commercial $\mathrm{MoS}_{2}$ as shown in Fig 3. Ding et al. introduced a simple and wellorganized technique to organize more efficient $\mathrm{MoS}_{2}$ materials. They arranged accurate $\mathrm{MoS}_{2}$ superstructure made up of nanosheets of $\mathrm{MoS}_{2}$. Good

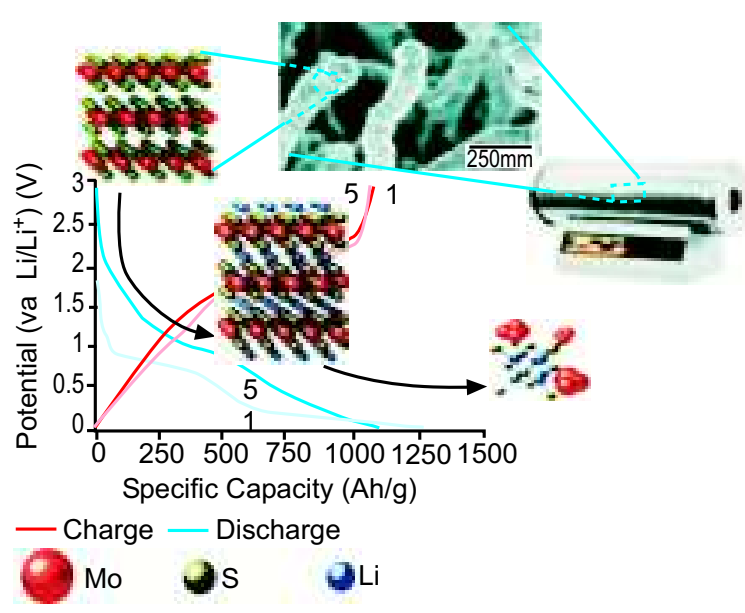

Fig. 3. Lithiated $1 \mathrm{~T}-\mathrm{MoS}_{2}$ showing lithium ions occupying octahedral interstices (Stephenson et al., 2014).

electrochemical presentation than the commercial $\mathrm{MoS}_{2}$ is achieved when as an anode material CLET $\mathrm{MoS}_{2}$ was functional in LIB's (Ding et al., 2016).

Super capacitors. Super capacitors are energy storage devices which are used to store electrical energy by fast surface redox reactions (Wang and Zhang, 2012; Zhang, and Zhang, 2012; Pandolfo and Hollenkamp, 2006; Kötz and Carlen, 2000). They have relative low cost and high-power density. They are of two types.

(i) Pseudo capacitors

(ii) Electrical double layer capacitors (EDLCs) Examples of EDLCs type of electrode is CNTs and graphene(Zhang and Zhao, 2009). Capacitance of pseudo capacitive materials is high than EDLCs type of electrodes because of reversible and fast transfer reactions. Very first work on $\mathrm{MoS}_{2}$ films for super capacitors as an electrode material was reported by Loh and Soon.

In $\mathrm{MoS}_{2}$ slight films charge storage can occur potentially in three modes principally as:

(i) Inner sheet double layer charge storage on individual atomic layer of $\mathrm{MoS}_{2}$ by diffusion.

(ii) Charge storage inner sheet double layer. (iii) On Mo transition metal centre faradaic charge transfer process (Soon and Loh, 2007).

Composites of $\mathrm{MoS}_{2}$ conducting polymer has shown enhanced performance of good cycling stability and high capacitance as reported by many researchers. In the field of super capacitors 2D-layered materials, $\mathrm{MoS}_{2}$ 
was consider important due to its corresponding structure of graphite. By chemical vapour authentication super capacitor performances of $\mathrm{MoS}_{2}$ films set and parallel to carbon nanotube arrays. Super capacitors have high energy compactness as compare to traditional capacitors, fast charge and discharge, high power density long cycle life and low cost. (Ratha and Rout, 2013; Soon and Loh, 2007) The $\mathrm{MoS}_{2}$ material was reported for fabrication of dye-sensitized solar cell. The $\mathrm{MoS}_{2}$ preparation with metal, non-metal and rare earth elements make a positive influence on the performance of DSSCs. For example, when dye-sensitized solar cell was assembling with $\mathrm{MoS}_{2} \mathrm{TiO}_{2}$ nanoparticles, the efficiency of solar cell was enhanced as compare to pure material. Broad applications including other electrochemical devices and beyond might be covered by the excellent performance of the hierarchical $\mathrm{MoS}_{2}$ super structure. Due to conductivity merge with intercalation of ion pseudo capacitance $1 \mathrm{~T}-\mathrm{MoS}_{2}$ phase can proceed as vastly competent super capacitor electrode objects.

Dye sensitized solar cells (DSSCs). One of the hopeful renewable energy devices is dye sensitized solar cells (DSSCs). DSSCs convert the solar energy into electrical energy and are the solution of energy problems in future. The advantages of solar cells are low cost, simple fabrication process, good plasticity and high flexibility (Grätzel, 2003). The excellent work of two scientists Graetzel and O'Regan reported in 1991. In international research community, work of Zhang et al. (2008), becomes a great attention. $\mathrm{MoS}_{2}$ using a method of solid-state sulfurization and used for DSSCs as CEs. $\mathrm{MoS}_{2}$ was prepared by Ho et al. (2004) (Jhang and Lin, 2015) by mixing purchase $\mathrm{MoS}_{2}$ with $\mathrm{TiO}_{2}$ nanoparticles for DSSCs. The efficiency of power restoration of fabricated DSSCs enriched from $2.54 \%$ to $5.08 \%$ by mixture of $\mathrm{TiO}_{2}$ and $\mathrm{MoS}_{2}$.

As contradict electrode patterned $\mathrm{MoS}_{2}$ and un-patterned $\mathrm{MoS}_{2}$ were assembled on the catalytic activity of atomic layers of $\mathrm{MoS}_{2}$ to examine the effect of active edge sites as shown in Fig 4. Comparison can be performed by using platinum electrode. The curves that are formed between photocurrent and voltage of solar cell devices are shown in Fig. 4 (Roy-Mayhew et al., 2012). Unpatterned $\mathrm{MoS}_{2}$ based devices have low current density as measure from platinum. The outcome of those devices which are based on ornate $\mathrm{MoS}_{2}$ is at a standstill lower than platinum.
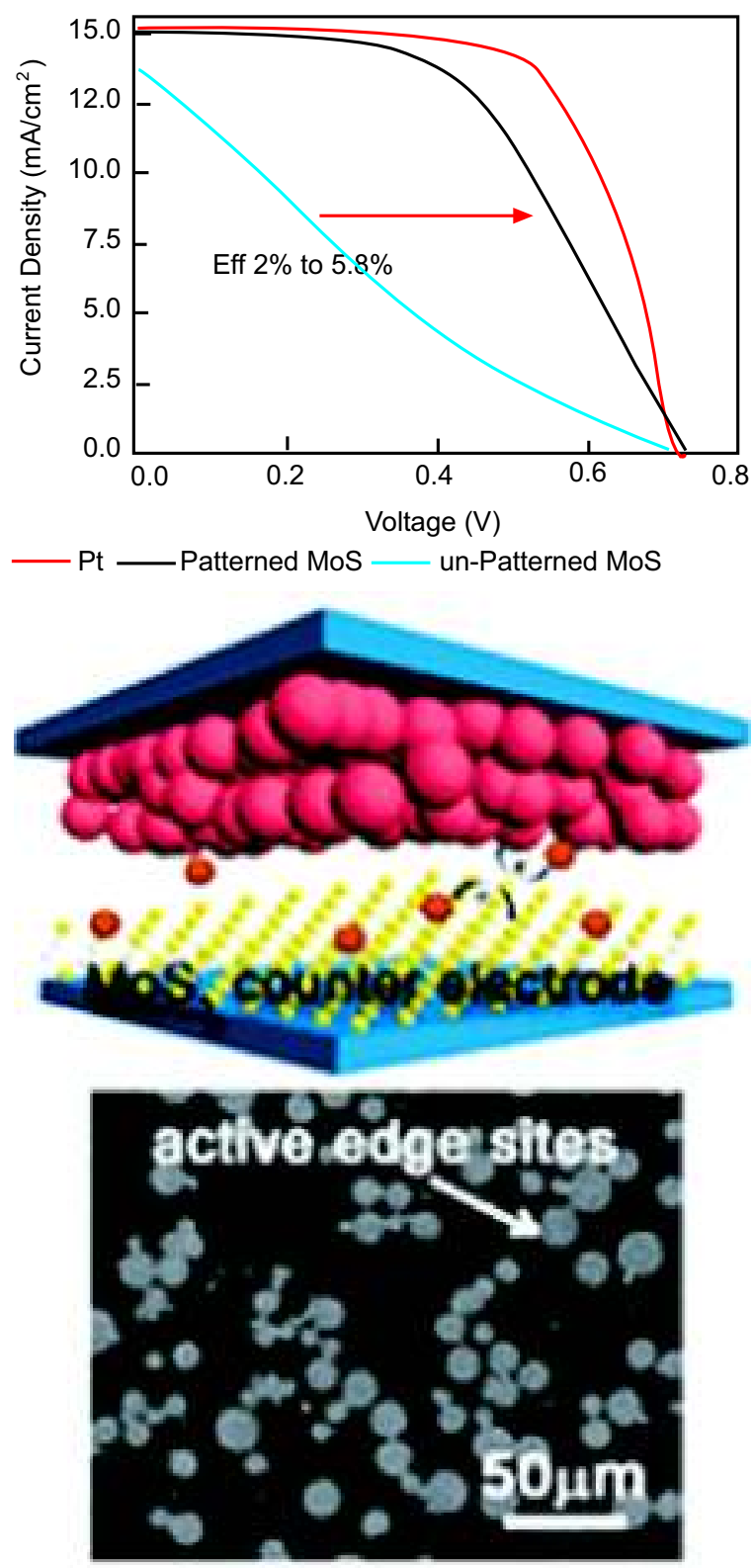

Fig. 4. A schematic diagram of a DSSC with $\mathrm{MoS}_{2}$ as counter electrode and voltage-density characteristic curves (Roy-Mayhew et al., 2012).

DSSC is a current tool which is used to change solar energy into electrical energy. For the energy related problems in future, it provides explanation at wide ranges. The typical DSSCs consists of dye synthesized $\mathrm{TiO}_{2}$ photo anode, $\mathrm{I}^{-} / \mathrm{I}^{-3}$ redox electrolytes counter electrode (CE) (Kwon et al., 2013; Chen et al., 2005) The splendid metal platinum $(\mathrm{Pt})$ is generally used as 
CE in DSSCs because it has surprising electro catalytic characteristic for $\mathrm{I}^{-3}$ decrease. $\mathrm{MoS}_{2}$ is one of the interesting materials due to its large quantity, prominent conductivity, easy production and extraordinary electrocatalytic activity. Kim et al. 2014 and 2015 reported that DSSCs accumulated with thermally preserved $\mathrm{MoS}_{2}$ at 100 show analogous power modification competence of $7.35 \%$. However, $\mathrm{MoS}_{2}$ over 300 showed considerable diminish in power adaptation success owing to its substance renovation (Kim et al., 2015).

Hydrogen evolution reaction (HER). For future energy needs, hydrogen is considered one of the best options as a clean fuel. $\mathrm{MoS}_{2}$ in which hydrogen will be produced that participates in the field of energy storage and it will be proved a good replacement of fusel fuels. In the atmosphere, the content of carbon dioxide will be more than double if only fossil fuels were exploited to meet the energy requirements, thereby increasing global warming. Research on renewable fuels is required to get rid from fossil fuels as energy source. In the recent years, hydrogen attained much attention for energy storage and conversion of solar to chemical energy. Production of hydrogen from renewable source, especially from water was a great challenge.

Generally, there are two ways for production of $\mathrm{H}_{2}$ as from steam reforming of methane and coal gasification. But these methods cause environmental pollution and costly. So, by splitting of water which is naturally abundant has forced the researchers to focus on

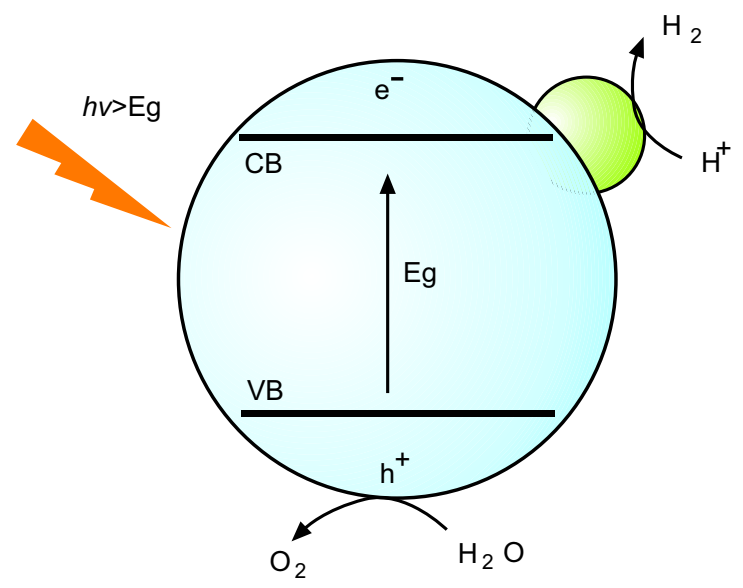

Fig. 5. Principle of photo electro-catalytic water splitting on a photo catalyst (Yuan et al., 2015). renewable and green resources of energy (Guo et al., 2016; Bose et al., 2015; Ma et al., 2015; Rowley-Neale et al., 2015; Yu et al., 2015; Zhang et al., 2015; Zhang et al., 2014). Protons in the electrolyte are absorbed and then reduced into $\mathrm{H}_{2}$ on the electrode; during the hydrogen evolution reaction process whenever potential is applied as shown in Fig. 5. A catalyst is required for the efficient production of $\mathrm{H}_{2}$. It was hypothesized that to activate the "inert" in plane $\mathrm{MoS}_{2}$, the in-plane doping of $\mathrm{MoS}_{2}$ is not ideal due to limited electron transport and limited active sites.

In addition, doping of $\mathrm{MoS}_{2}$ with atoms or materials can enlarge the inter layer spacing of $\mathrm{MoS}_{2}$ and alter the Basel planes and thus modify their d-band electronic properties. $\mathrm{MoS}_{2}$ was discovered in 1977 for HER but it was ignored due to its bulk form (Tributsch, 1977). In 2005, $\mathrm{MoS}_{2}$ was reported as gifted HER catalyst. Tributsch and co-workers worked on natural catalyst of $\mathrm{MoS}_{2}$ for electrochemical hydrogen evolution. Very little studies have reported foremost restriction on the straight use of $\mathrm{MoS}_{2}$ as a photo catalyst for HER is the low action. For photo induce water splitting, ordinary semiconductor equipment as CdS (Zong et al., 2008), $\mathrm{TiO}_{2}$, and $\mathrm{Cu}_{2} \mathrm{O}$ (Tran et al., 2012) can be used. There are a lot of dis advantages of these materials. The band gap of $\mathrm{TiO}_{2}$ is very minute, so it sucks up only small partition of sun light. Much work is needed to triumph over these troubles by amendment of photo catalysis. For HER under visible light, Frame and Osterloh premeditated the property of photo catalytic CdS. The first exclusive right was published in 1980 (Haering et al., 1980) of $\mathrm{MoS}_{2}$ based LIB. Searching this apparatus by Bonde et al. (2009) and they found the rim of $\mathrm{MoS}_{2}$ coating and vacancy fashioned by $\mathrm{S}$ atoms on edge sites, contributed to the electrocatalytic activity of $\mathrm{MoS}_{2}$. They also suggested that by the morphology convenient synthesis course of action, the active edge of $\mathrm{MoS}_{2}$ are increasing and this procedure may get better the electrocatalytic exploit of $\mathrm{MoS}_{2}$ in electrochemical HER (Bonde et al., 2009).

$\mathrm{MoS}_{2}$ for solar water splitting. One of the gifted solutions is photo catalytic $\mathrm{H}_{2}$ evolution from water using sunlight to address the increasing energy needs. Because of low quantum effectiveness, production of $\mathrm{H}_{2}$ is quite challenging. In the field of $\mathrm{H}_{2}$ production by water splitting, semiconductor have received much attention. Water splitting derived by sunlight was one 


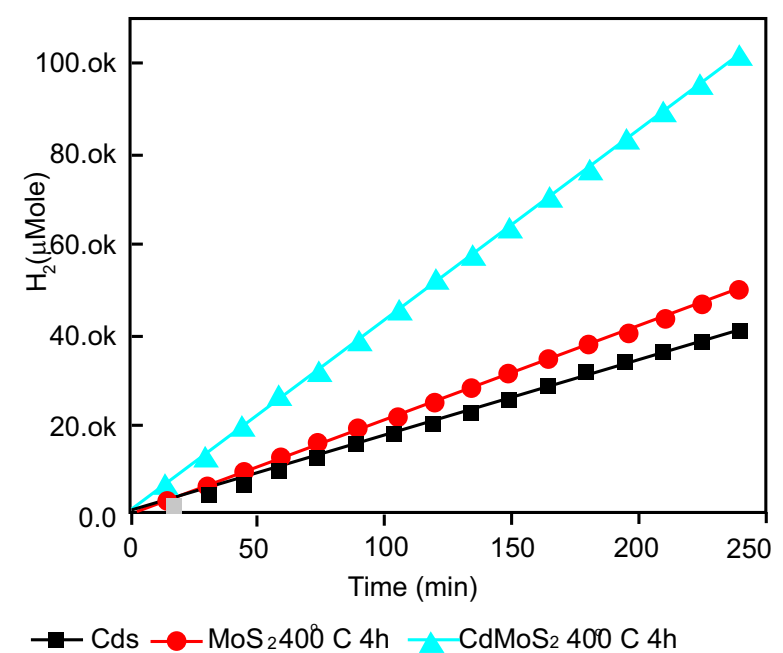

Fig. 6. Photocatalytic $\mathrm{H}_{2}$ generation activity plot $\mathrm{H}_{2} \mathrm{~S}$ over $\mathrm{MoS}_{2}$ and CdS (Kadam et al., 2015).

of the most attractive methods to produce hydrogen for energy storage. Enhancing the energy requirements without infusing the environmental pollution will be a great challenge. The reaction of water splitting was expressed as:

$$
\mathrm{H}_{2} \mathrm{O} \rightarrow \mathrm{H}_{2}+12 \mathrm{O}_{2} \Delta \mathrm{G}_{298 \mathrm{k}}^{0}=2.37 \mathrm{~kJ} / \mathrm{mol}
$$

Water splitting requires energy of $2.37 \mathrm{~kJ} / \mathrm{mol}$ for HER that will be lowered with the help of appropriate catalyst. Thermodynamic voltage requirement of $1.23 \mathrm{~V}$ was corresponding by the input energy of that reaction. The



Fig. 7. The rate of $\mathrm{H}_{2}$ evolution on $\mathrm{MoS}_{2} / \mathrm{Cd} \mathrm{S}$ photo catalysts loaded with different amount of $\mathrm{MoS}_{2}$ under visible light (Sobczynski, 1991). needs of photo catalyst are following: low cost, must be photostable, capable of storing more solar energy. $\mathrm{MoS}_{2}$ is an important photo catalyst due to its exceptional properties. $\mathrm{MoS}_{2}$ has shown great development as a photo catalyst with $\mathrm{H}_{2}$ production by water splitting as revealed in Fig. 6 (Kadam et al., 2015). Jia et al., (2015) Esin Y (EY) modified $\mathrm{MoS}_{2}$ photo catalytic $\mathrm{H}_{2}$ evolution by water splitting.

The attractive and exigent topic is production of photo catalytic $\mathrm{H}_{2}$ using semiconductor (Zong et al., 2008). Photo catalysts consist of co-catalysts and semiconductor materials. In the production of $\mathrm{H}_{2}$ and $\mathrm{O}_{2}$, there is important role of co-catalysts. The activities of photo catalysts can greatly enhance by loading of paper cocatalysts. By loading $\mathrm{MoS}_{2}$ as a catalyst, it is found that role of $\mathrm{CdS}$ can be extend, under the same reaction condition, it is shown that activity of $\mathrm{Pt} / \mathrm{CdS}$ is even lower than that of $\mathrm{MoS}_{2} / \mathrm{CdS}$ as shown in Fig. 5. It is recommended that $\mathrm{MoS}_{2}$ is not active for photo catalytic $\mathrm{H}_{2}$ evolution because when alone $\mathrm{MoS}_{2}$ is used as catalyst, no $\mathrm{H}_{2}$ was detected. The activity of $\mathrm{H}_{2}$ evolution increased up to 22 times, when only $0.01 \%$ of $\mathrm{MoS}_{2}$ on $\mathrm{CdS}$ is added.

After loading $\mathrm{Cd} \mathrm{S}$ by $\mathrm{MoS}_{2}$ of 0.2 wt.\% commotion is 36 times enlarged. The activity also appears maximum by using other photo catalysts as $\mathrm{Pd}, \mathrm{Pt}, \mathrm{Ru}$ and $\mathrm{RuO}_{2}$. The double peaks in MoS2/CdS indicate the formation of $\mathrm{MoS}_{2}$ (Ho et al., 2004) as shown in Fig. 7.

The photo catalyst in trellis acid solution are shown under visible light (lambda $>420 \mathrm{~nm}$ ). For $\mathrm{H}_{2}$ or $\mathrm{O}_{2}$ evolution, co-catalysts offer low activation potentials and obtainable for $\mathrm{H}_{2}$ or $\mathrm{O}_{2}$ generation as active sites. Consequently the behavior of photo catalysts are improved by loading of proper co-catalysts (Zong et al., 2008).

$\mathrm{Cd} \mathrm{MoS}_{2}$ conferred at rates of $25445 \mathrm{~mol} / \mathrm{g} / \mathrm{H}_{2}$ fruition and $\mathrm{MoS}_{2}$ as at rate of $12555 \mathrm{~mol} / \mathrm{g}$. Cd MoS 2 and $\mathrm{MoS}_{2}$ nanostructures were used for $\mathrm{H}_{2}$ production with quantum yields of $35.34 \%$ and $17.18 \%$ respectively. For $\mathrm{H}_{2}$ production, a well-organized photo catalyst was used by method of chemical vapour deposition on $\mathrm{Au} @ \mathrm{Ag}$ nano rattles deposited on $\mathrm{MoS}_{2}$ (Kang et al., 2015). An enhanced photo catalytic activity is exhibited by ternary Cd MoS 4 than $\mathrm{MoS}_{2}$ and $\mathrm{Cd} \mathrm{S}$ untouched, due to combining positive effect of $\mathrm{MoS}_{2}$ and $\mathrm{Cd} \mathrm{S}$. By impregnating $\mathrm{Cd} \mathrm{S}$ with an aqueous solution of $\left(\mathrm{NH}_{4}\right)$ $\mathrm{MoS}_{4}$ with highly detached $\mathrm{MoS}_{2}$ on Cd S, MoS $3 / \mathrm{CdS}$ 


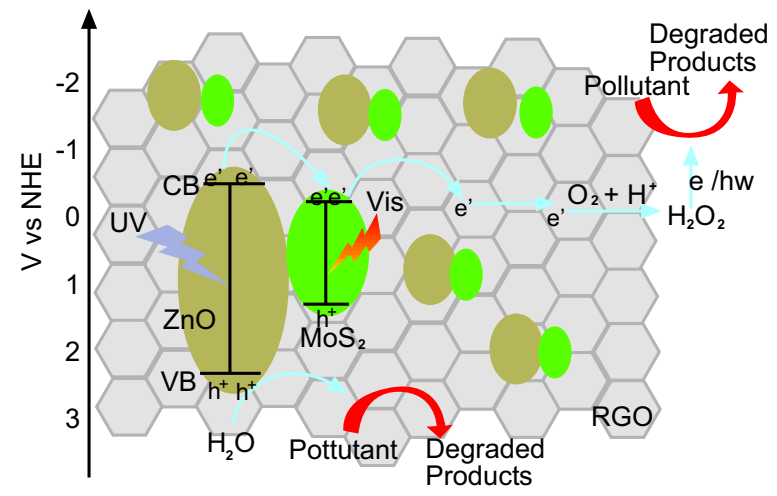

Fig. 8. Mechanisms of possible retardation for MB over $\mathrm{MoS}_{2}-\mathrm{ZnO}-\mathrm{RGO}$ hetero structure under irradiation of sunlight (Kumar et al., 2016).

catalysts prepared by using method of $\mathrm{H}_{2} \mathrm{~S}$ flow at high temperatures for $2 \mathrm{~h}$. Both cubic and hexagonal phases of $\mathrm{Cd} \mathrm{S}$ after treatment at $573 \mathrm{~K}$ are present in $\mathrm{Cd} \mathrm{S}$ and $\mathrm{MoS}_{2} / \mathrm{Cd} \mathrm{S}$ samples $1 \mathrm{wt} \% \mathrm{MoS}_{2} / \mathrm{Cd} \mathrm{S}$ was investigated by HRTEM, to visualize the junction structure of $\mathrm{MoS}_{2}$ and $\mathrm{Cd} \mathrm{S}$.

Degradation of photo catalytic organic pollutants. In the area of ecological redress and energy storage space, the advancement of nanostructured solar energy provoked photo catalysis of semiconductor has established much concentration. Oxygen levels that conduct to many problems in ecosystem can be changed by organic impurity that in attendance in wastewater. One of the efficient ways to get rid of the organic pollutant from wastewater is photo catalytic deprivation. Although, $\mathrm{TiO}_{2}$ is consider more efficient which manage its practical application only under UV light (Han et al., 2014; He et al., 2014). $\mathrm{MoS}_{2}$ has shown great attention in this field due to its environmentally gracious, its nontoxicity and its absorption matching to solar spectrum and due to its stability against photo catalyst. Jeo et al supported $\mathrm{TiO}_{2} / \mathrm{g}-\mathrm{C}_{3} \mathrm{~N}_{4} \mathrm{MoS}_{2}$ photo catalysts by scheme of wet impregnation and for degradation of methylene blue in employ it as obvious light active photo catalytic. For the elimination of organic pollutants in wastewater driven semiconductor photo catalysts that are based on solar light synthesized $\mathrm{ZnO}-\mathrm{MoS}_{2}-$ RGO. $\mathrm{MoS}_{2}$ decorated by two steps progression with $\mathrm{SnO}_{2}$ mesoporous nanoparticles prepared by Vattikuti et al., 2015.

The intensification of photo catalytic activity was because of developed electron hole-pair partition at $\mathrm{TiO}_{2} / \mathrm{g}-\mathrm{C}_{3} \mathrm{~N}_{4}$. Interface imparted through z-scheme electron transfer presented by Kumar et al (Kumar et al., 2016) as shown in Fig. 7.

By using method of hydrothermal composite catalysts were prepared and are used to find out the optimum levels of $\mathrm{ZnO}$ nanoparticles doping in heterostructures of $\mathrm{ZnO}-\mathrm{MoS}_{2}-\mathrm{RGO}$. When $\mathrm{ZnO}$ nanoparticles are doped with $1 \mathrm{wt} \% \mathrm{MoS}_{2}-\mathrm{RGO}$ there is most favourable and superior photo catalytic performance to eliminate the organic pollutants. By using simple method as hydrothermal. Wang et al. (Wang and Zhang, 2015) synthesized flower like $\mathrm{MoS}_{2} / \mathrm{CdS}$ heterostructures. $\mathrm{Li}$ et al., proposed that, $\mathrm{MoS}_{2}$ and $\mathrm{Ag}_{3} \mathrm{VO}_{2}$ are used by using two-step hydrothermal route and by explore photo catalytic performances for degradation of MB under visible light irradiation. $\mathrm{MoS}_{2} / \mathrm{CuO}$ heterogeneous nano flower structure synthesized. Due to vigorous edge sites of porous $\mathrm{MoS}_{2}$ towards the dreadful conditions of MB, porous $\mathrm{MoS}_{2}$ showed attractive photo catalytic activity without any outline, porous $\mathrm{MoS}_{2}$ is synthesized, and explained by Zhou et al. (2014). By procedure of hydrothermal without any pattern, porous $\mathrm{MoS}_{2}$ was synthesized. Owed to energetic boundary sites of absorbent $\mathrm{MoS}_{2}$ the porous $\mathrm{MoS}_{2}$ exhibited eye-catching photo catalytic activity towards poverty of MB. Jeo et al. (2016) prepared $\mathrm{MoS}_{2}$ nanosheets loaded composites ZnO-g- $\mathrm{C}_{3} \mathrm{~N}_{4}$ and $\mathrm{ZnO}-\mathrm{g}-\mathrm{C}_{3} \mathrm{~N}_{4}$ nanocomposites for photo catalytic dreadful conditions of atropine and $\mathrm{MB}$ in aqueous solution.

\section{Conclusion}

By numerous researchers, the application and alternation of coated $\mathrm{MoS}_{2}$ nanostructured supplies has been found. (Akbari et al., 2018; Kukkar et al., 2018) In this appraisal, we have calculated about modern progress in the field of $\mathrm{MoS}_{2}$. Applications of $\mathrm{MoS}_{2}$ at a wide range start from their chemical properties as enormous surface area, mechanical discovery and excellent charge reposition property. HER recital principally depends upon the inclination of catalyst with having strong necessary energy for absorbed $\mathrm{H}^{+}$. Due to gapless band structure graphene was not suitable electronic material. $\mathrm{MoS}_{2}$ was a closest competitor of graphene and used as its substitute, because of its reasonable energy gap, mechanical flexibility, absence of dangling bonds and chemical and thermal stability. Due to positive synthetic strategies, $\mathrm{MoS}_{2}$ composites show high energetic boundary sites. It has different compensating ways over other catalysts as no toxicity, ability to assemble electron hole-pair for photo catalysis and low cost. 
Pt is used at a wide range in DSSCs which gives best presentation for electrocatalytic decrease of $\overline{\mathrm{I}}$ to $\overline{\bar{I}}_{3}$ ions. But $\mathrm{Pt}$ is very costly and due to this reason in liquid state $\bar{I}$ to $\overline{I_{3}}$ redox electrolyte has imperfect its applications in DSSCs. These properties of Pt have forced the researchers to find the alternative of Pt. So, researchers have paying attention on $\mathrm{MoS}_{2}$. MoS 2 has excellent properties and incredible potential. Composites of $\mathrm{MoS}_{2}$ have set up to illustrate superior energy storage properties with porous structures. Characteristic layered $\mathrm{MoS}_{2}$ are measured comprehensively well-organized applicant for sensor applications. $\mathrm{MoS}_{2}$ has large surface area and its benefit is assimilation of molecules on surface of $\mathrm{MoS}_{2}$. Weak Van Dar Waals interface in $\mathrm{MoS}_{2}$ structure permits the atoms carry liberally in $\mathrm{MoS}_{2} . \mathrm{MoS}_{2}$ materials are exceptional substrates for applications of energy and surroundings. However, more work is needed on $\mathrm{MoS}_{2}$.

Conflict of Interest. The authors declare no conflict of interest.

\section{References}

Akbari, E., Jahanbin, K., Afroozeh, A., Yupapin, P., Buntat, Z. 2018. Brief review of monolayer molybdenum disulfide application in gas sensor. Physica B: Condensed Matter, 545: 510-518.

Arshad, M.M., Gopinath, S.C., Norhaimi, W., Fathil, M. 2019. Current and future envision on developing biosensors aided by 2D molybdenum disulfide $\left(\mathrm{MoS}_{2}\right)$ productions. Biosensors and Bioelectronics.

Benavente, E., Santa, A.M., Mendizábal, F., González, G. 2002. Intercalation chemistry of molybdenum disulfide. Coordination Chemistry Reviews, 224: 87-109.

Bonde, J., Moses, P.G., Jaramillo, T.F., Nørskov, J.K., Chorkendorff, I. 2009. Hydrogen evolution on nano-particulate transition metal sulfides. Faraday Discussions, 140: 219-231.

Bose, R., Balasingam, S.K., Shin, S., Jin, Z., Kwon, D. H., Jun, Y. 2015. Importance of hydrophilic pretreatment in the hydrothermal growth of amorphous molybdenum sulfide for hydrogen evolution catalysis. Langmuir, 31: 5220-5227.

Butler, S.Z., Hollen, S.M., Cao, L., Cui, Y., Gupta, J. A., Gutiérrez, H.R. 2013 Progress, challenges, and opportunities in two-dimensional materials beyond graphene. ACS Nano, 7: 2898-2926.
Chen, J., Ma, Y., Wang, G., Wang, Z., Zhou, X., Lin, Y. 2005. A novel method for preparing platinized counter electrode of nanocrystalline dye-sensitized solar cells. Chinese Science Bulletin, 50: 11-14.

Chhowalla, M., Shin, H. S., Eda, G., Li, L.-J., Loh, K. P., Zhang, H. 2013. The chemistry of twodimensional layered transition metal dichalcogenide nanosheets. Nature Chemistry, 5: 263.

Ding, J., Zhou, Y., Li, Y., Guo, S., Huang, X. 2016. $\mathrm{MoS}_{2}$ nanosheet assembling superstructure with a three-dimensional ion accessible site: a new class of bifunctional materials for batteries and electrocatalysis. Chemistry of Materials, 28: 2074-2080.

Ge, M., Cao, C., Huang, J., Li, S., Chen, Z., Zhang, K.Q. et al. 2016. A review of one-dimensional $\mathrm{TiO}_{2}$ nanostructured materials for environmental and energy applications. Journal of Materials Chemistry A, 4: 6772-6801.

Goloveshkin, A.S., Bushmarinov, I.S., Lenenko, N.D., Buzin, M.I., Golub, A. S., Antipin, M. Y. 2013. Structural properties and phase transition of exfoliated-restacked molybdenum disulfide. The Journal of Physical Chemistry C, 117: 8509-8515.

Grätzel, M. 2003. Dye-sensitized solar cells. Journal of Photochemistry and Photobiology C: Photochemistry Reviews, 4: 145-153.

Guo, Z., Ma, Q., Xuan, Z., Du, F., Zhong, Y. 2016. Facile surfactant-assisted synthesis of CTABincorporated $\mathrm{MoS}_{2}$ ultrathin nanosheets for efficient hydrogen evolution. RSC Advances, 6: 1673016735.

Haering, R.R., Stiles, J.A., Brandt, K. 1980. Lithium molybdenum disulphide battery cathode: Google Patents.

Han, C., Ge, L., Chen, C., Li, Y., Xiao, X., Zhang, Y. 2014. Novel visible light induced $\mathrm{Co}_{3} \mathrm{O}_{4}-\mathrm{g}-\mathrm{C}_{3} \mathrm{~N}_{4}$ heterojunction photocatalysts for efficient degradation of methyl orange. Applied Catalysis B: Environmental, 147: 546-553.

He, Y., Zhang, L., Wang, X., Wu, Y., Lin, H., Zhao, L. 2014. Enhanced photodegradation activity of methyl orange over $\mathrm{Z}$-scheme type $\mathrm{MoO} 3-\mathrm{gC}_{3} \mathrm{~N}_{4}$ composite under visible light irradiation. $R S C$ Advances, 4: 13610-13619.

Ho, W., Yu, J.C., Lin, J., Yu, J., Li, P. 2004. Preparation and photocatalytic behavior of $\mathrm{MoS}_{2}$ and $\mathrm{WS}_{2}$ nanocluster sensitized $\mathrm{TiO}_{2}$. Langmuir, 20: 58655869 . 
Imanishi, N., Kanamura, K., Takehara, Z. I. 1992. Synthesis of $\mathrm{MoS}_{2}$ thin film by chemical vapour deposition method and discharge characteristics as a cathode of the lithium secondary battery. Journal of the Electrochemical Society, 139: 2082-2087.

Jhang, W.-H., Lin, Y.-J. 2015. Interface modification of $\mathrm{MoS}_{2}$ counter electrode/electrolyte in dyesensitized solar cells by incorporating $\mathrm{TiO}_{2}$ nanoparticles. Current Applied Physics, 15: 906909.

Jia, T., Li, M.M., Ye, L., Wiseman, S., Liu, G., Qu, J. 2015. The remarkable activity and stability of a dye-sensitized single molecular layer $\mathrm{MoS}_{2}$ ensemble for photocatalytic hydrogen production. Chemical Communications, 51: 13496-13499.

Jo, W.-K., Lee, J.Y., Selvam, N.C.S. 2016. Synthesis of $\mathrm{MoS}_{2}$ nanosheets loaded $\mathrm{ZnO}-\mathrm{g}-\mathrm{C}_{3} \mathrm{~N}_{4}$ nanocomposites for enhanced photocatalytic applications. Chemical Engineering Journal, 289: 306-318.

Kadam, S.R., Late, D.J., Panmand, R.P., Kulkarni, M.V., Nikam, L.K., Gosavi, S. W.2015. Nanostructured $2 \mathrm{D} \mathrm{MoS}_{2}$ honeycomb and hierarchical 3D Cd MoS 4 marigold nanoflowers for hydrogen production under solar light. Journal of Materials Chemistry A, 3: 21233-21243.

Kang, Y., Gong, Y., Hu, Z., Li, Z., Qiu, Z., Zhu, X. 2015. Plasmonic hot electron enhanced $\mathrm{MoS}_{2}$ photocatalysis in hydrogen evolution. Nanoscale, 7: 4482-4488.

Kim, J. S., Han, H.S., Shin, S., Han, G.S., Jung, H.S., Hong, K.S. 2014. In $2 \mathrm{O}_{3}$ : $\mathrm{Sn} / \mathrm{TiO}_{2} / \mathrm{CdS}$ heterojunction nanowire array photoanode in photoelectrochemical cells. International Journal of Hydrogen Energy, 39: 17473-17480.

Kim, S.-S., Lee, J.-W., Yun, J.-M., \& Na, S.-I. 2015. 2Dimensional $\mathrm{MoS}_{2}$ nanosheets as transparent and highly electrocatalytic counter electrode in dyesensitized solar cells: effect of thermal treatments. Journal of Industrial and Engineering Chemistry, 29: 71-77.

Koma, A., Yoshimura, K. 1986. Ultrasharp interfaces grown with Van der Waals epitaxy. Surface Science, 174: 556-560.

Kötz, R., Carlen, M. 2000. Principles and applications of electrochemical capacitors. Electrochimica Acta, 45: 2483-2498.

Kukkar, M., Mohanta, G.C., Tuteja, S.K., Kumar, P.,
Bhadwal, A.S., Samaddar, P. 2018. A comprehensive review on nano-molybdenum disulfide/DNA interfaces as emerging biosensing platforms. Biosensors and Bioelectronics, 107: 244-258.

Kumar, S., Sharma, V., Bhattacharyya, K., Krishnan, V. 2016. Synergetic effect of $\mathrm{MoS}_{2}-\mathrm{RGO}$ doping to enhance the photocatalytic performance of $\mathrm{ZnO}$ nanoparticles. New Journal of Chemistry, 40: 5185 5197.

Kwon, J., Ganapathy, V., Kim, Y.H., Song, K.-D., Park, H.-G., Jun, Y. 2013. Nanopatterned conductive polymer films as a Pt, TCO-free counter electrode for low-cost dye-sensitized solar cells. Nanoscale, 5: 7838-7843.

Long, L., Wang, S., Xiao, M., Meng, Y. 2016. Polymer electrolytes for lithium polymer batteries. Journal of Materials Chemistry A, 4: 10038-10069.

Lou, X.W., Deng, D., Lee, J.Y., Feng, J., Archer, L.A. 2008. Self-supported formation of need lelike $\mathrm{Co}_{3} \mathrm{O}_{4}$ nanotubes and their application as lithium-ion battery electrodes. Advanced Materials, 20: 258262.

Ma, L., Zhou, X., Xu, X., Xu, L., Zhang, L., Chen, W. 2015. One-step hydrothermal synthesis of fewlayered and edge-abundant $\mathrm{MoS}_{2} / \mathrm{C}$ nanocomposites with enhanced electrocatalytic performance for hydrogen evolution reaction. Advanced Powder Technology, 26: 1273-1280.

Novoselov, K.S., Geim, A.K., Morozov, S.V., Jiang, D., Zhang, Y., Dubonos, S.V. 2004. Electric field effect in atomically thin carbon films. Science, 306: 666-669.

Pandolfo, A., Hollenkamp, A. 2006. Carbon properties and their role in super capacitors. Journal of Power Sources, 157: 11-27.

Qu, B., Sun, Y., Liu, L., Li, C., Yu, C., Zhang, X. 2017. Ultrasmall $\mathrm{Fe}_{2} \mathrm{O}_{3}$ nanoparticles/ $\mathrm{MoS}_{2}$ nanosheets composite as high-performance anode material for lithium ion batteries. Scientific Reports, 7: 42772.

Ratha, S., Rout, C.S. 2013. Supercapacitor electrodes based on layered tungsten disulfide-reduced graphene oxide hybrids synthesized by a facile hydrothermal method. ACS Applied Materials \& Interfaces, 5: 11427-11433.

Rowley-Neale, S. J., Brownson, D.A., Smith, G.C., Sawtell, D.A., Kelly, P.J., Banks, C.E. 2015. 2D nanosheet molybdenum disulphide $\left(\mathrm{MoS}_{2}\right)$ modified electrodes explored towards the hydrogen evolution 
reaction. Nanoscale, 7: 18152-18168.

Roy-Mayhew, J.D., Boschloo, G., Hagfeldt, A., Aksay, I. A. 2012. Functionalized graphene sheets as a versatile replacement for platinum in dye-sensitized solar cells. ACS Applied Materials and Interfaces, 4: 2794-2800.

Santhosh, S., Madhavan, A.A. 2019. A review on the structure, properties and characterization of $2 \mathrm{D}$ molybdenum disulfide. Paper presented at the 2019 Advances in Science and Engineering Technology International Conferences (ASET).

Shi, Y., Wang, Y., Wong, J.I., Tan, A.Y.S., Hsu, C.-L., Li, L.-J. 2013. Self-assembly of hierarchical MoS $\mathrm{x} / \mathrm{CNT}$ nanocomposites $(2<\mathrm{x}<3)$ : towards high performance anode materials for lithium ion batteries. Scientific Reports, 3: 2169.

Snyder, E.G., Watkins, T.H., Solomon, P.A., Thoma, E.D., Williams, R.W., Hagler, G.S. 2013. The changing paradigm of air pollution monitoring: ACS Publications.

Sobczynski, A. 1991. Molybdenum disulfide as a hydrogen evolution catalyst for water photo decomposition on semi conductors. Journal of Catalysis, 131: 156-166.

Soon, J. M., Loh, K. P. 2007. Electrochemical doublelayer capacitance of $\mathrm{MoS}_{2}$ nanowall films. Electrochemical and Solid-State Letters, 10: A250A254.

Stephenson, T., Li, Z., Olsen, B., Mitlin, D. 2014. Lithium ion battery applications of molybdenum disulfide $\left(\mathrm{MoS}_{2}\right)$ nanocomposites. Energy \& Environmental Science, 7: 209-231.

Tran, P. D., Batabyal, S.K., Pramana, S.S., Barber, J., Wong, L.H., Loo, S.C.J. 2012. A cuprous oxidereduced graphene oxide $\left(\mathrm{Cu}_{2} \mathrm{O}-\mathrm{rGO}\right)$ composite photocatalyst for hydrogen generation: employing $\mathrm{GO}$ as an electron acceptor to enhance the photocatalytic activity and stability of $\mathrm{Cu}_{2} \mathrm{O}$. Nanoscale, 4: 3875-3878.

Tributsch, H. 1977. Layer-type transition metal dichalcogenides-a new class of electrodes for electrochemical solar cells. Berichte der Bunsengesellschaft Für Physikalische Chemie, 81: 361369.

Vattikuti, S.P., Byon, C., Reddy, C.V., Ravikumar, R. 2015. Improved photocatalytic activity of $\mathrm{MoS}_{2}$ nanosheets decorated with $\mathrm{SnO}_{2}$ nanoparticles. $R S C$ Advances, 5: 86675-86684.
Wang, C., Lin, H., Xu, Z., Cheng, H., Zhang, C. 2015. One-step hydrothermal synthesis of flower like $\mathrm{MoS}_{2} / \mathrm{CdS}$ heterostructures for enhanced visiblelight photocatalytic activities. RSC Advances, 5: 15621-15626.

Wang, G., Zhang, L., Zhang, J. 2012. A review of electrode materials for electrochemical supercapacitors. Chemical Society Reviews, 41: 797-828.

Xia, D.D., Gong, F., Pei, X., Wang, W., Li, H., Zeng, W. 2018. Molybdenum and tungsten disulfidesbased nanocomposite films for energy storage and conversion: A review. Chemical Engineering Journal, 348: 908-928.

Xiong, P., Zhu, J., Zhang, L., Wang, X. 2016. Recent advances in graphene-based hybrid nanostructures for electrochemical energy storage. Nanoscale Horizons, 1: 340-374.

Yu, H., Yu, X., Chen, Y., Zhang, S., Gao, P., Li, C. 2015. A strategy to synergistically increase the number of active edge sites and the conductivity of $\mathrm{MoS}_{2}$ nanosheets for hydrogen evolution. Nanoscale, 7: 8731-8738.

Yu, H., Zhu, C., Zhang, K., Chen, Y., Li, C., Gao, P. 2014. Three-dimensional hierarchical $\mathrm{MoS}_{2}$ nanoflake array/carbon cloth as high-performance flexible lithium-ion battery anodes. Journal of Materials Chemistry A, 2: 4551-4557.

Yuan, Y., Lu, H., Ji, Z., Zhong, J., Ding, M., Chen, D. 2015. Enhanced visible-light-induced hydrogen evolution from water in a noble-metal-free system catalyzed by $\mathrm{ZnTCPP}-\mathrm{MoS}_{2} / \mathrm{TiO}_{2}$ assembly. Chemical Engineering Journal, 275: 8-16.

Zeng, Z., Yin, Z., Huang, X., Li, H., He, Q., Lu, G. 2011. Single-layer semiconducting nanosheets: high-yield preparation and device fabrication. Angewandte Chemie, 123: 11289-11293.

Zhang, G., Liu, H., Qu, J., Li, J. 2016. Two-dimensional layered $\mathrm{MoS}_{2}$ : rational design, properties and electrochemical applications. Energy \& Environmental Science, 9: 1190-1209.

Zhang, K., Zhao, Y., Zhang, S., Yu, H., Chen, Y., Gao, P. 2014. $\mathrm{MoS}_{2}$ nanosheet/Mo $\mathrm{Mo}_{2} \mathrm{C}$-embedded Ndoped carbon nanotubes: synthesis and electrocatalytic hydrogen evolution performance. Journal of Materials Chemistry A, 2: 18715-18719.

Zhang, L. L., Zhao, X. 2009. Carbon-based materials as supercapacitor electrodes. Chemical Society 
Reviews, 38: 2520-2531.

Zhang, S., Yu, X., Yu, H., Chen, Y., Gao, P., Li, C. 2014.

Growth of ultrathin $\mathrm{MoS}_{2}$ nanosheets with expanded spacing of (002) plane on carbon nanotubes for high-performance sodium-ion battery anodes. $A C S$ Applied Materials \& Interfaces, 6: 21880-21885.

Zhang, Z., Li, W., Yuen, M.F., Ng, T.-W., Tang, Y., Lee, C.-S. 2015. Hierarchical composite structure of few-layers $\mathrm{MoS}_{2}$ nan osheets supported by vertical graphene on carbon cloth for high-performance hydrogen evolution reaction. Nano Energy, 18: 196-204.

Zhou, Z., Lin, Y., Zhang, P., Ashalley, E., Shafa, M.,
Li, H. 2014. Hydrothermal fabrication of porous $\mathrm{MoS}_{2}$ and its visible light photocatalytic properties. Materials Letters, 131: 122-124.

Zhu, X.-J., Hu, J., Dai, H.-L., Ding, L., Jiang, L. 2012. Reduced graphene oxide and nanosheet-based nickel oxide microsphere composite as an anode material for lithium ion battery. Electrochimica Acta, 64: 23-28.

Zong, X., Yan, H., Wu, G., Ma, G., Wen, F., Wang, L. 2008. Enhancement of photocatalytic $\mathrm{H}_{2}$ evolution on CdS by loading $\mathrm{MoS}_{2}$ as cocatalyst under visible light irradiation. Journal of the American Chemical Society, 130: 7176-7177. 